\title{
Subcostal TAPSE: a retrospective analysis of a novel right ventricle function assessment method from the subcostal position in patients with sepsis
}

\author{
Alison B. Main ${ }^{1}$, Rachel Braham², Daniel Campbell ${ }^{3}$, Andrew J. Inglis ${ }^{4}$, Anthony McLean ${ }^{5}$ and Sam Orde $5^{*}$
}

\begin{abstract}
Background: Tricuspid annular plane systolic excursion (TAPSE) is frequently used as an objective measure of rightventricular dysfunction. Abnormal TAPSE values are associated with poor prognosis in a number of disease states; however, the measure is not always easy to obtain in the critically ill. The purpose of this study is to assess the feasibility and accuracy of using a subcostal view and TAPSE measurement as a measure of right-ventricular dysfunction. A secondary aim was to perform a pilot study to assess whether right-ventricular dysfunction was associated with adverse outcomes including mortality.
\end{abstract}

Results: Subcostal TAPSE corresponds well with TAPSE obtained from the apical window at low and moderate TAPSE values (mean difference $1.2 \mathrm{~mm}$ (Cl 0.04-2.36; 100\% data pairs $<3-\mathrm{mm}$ difference for TAPSE $<19 \mathrm{~mm} ; 92 \% \mathrm{had}<3 \mathrm{~mm}$ difference at TAPDE $<24 \mathrm{~mm}$ ). Subcostal TAPSE is able to accurately discriminate between abnormal and normal TAPSE results (sensitivity $97.8 \%$, specificity $87.5 \%$ ). There was no association between right-ventricular (RV) dysfunction and 90-day mortality.

Conclusions: Subcostal TAPSE is a feasible and accurate alternative to conventional TAPSE from the apical view in critically ill patients. Further research is required to elucidate the relationship between RV dysfunction and outcomes in sepsis.

Keywords: Apical four chamber, Right ventricle, Sepsis, Subcostal, Tricuspid annular plane systolic excursion

\section{Background}

Reversible global myocardial depression is common and occurs early in sepsis and septic shock [1-4]. Echocardiography in the intensive-care unit (ICU) is a crucial tool for the assessment of cardiac function as it is non-invasive, safe, portable, and provides real-time information [5]. However, acquiring images can be challenging in the critically ill, particularly the apical view [6] limiting accurate cardiac assessment [7].

The importance of the role of right ventricle (RV) in the management of the critically ill is being increasingly

\footnotetext{
${ }^{*}$ Correspondence: Sam.orde@health.nsw.gov.au

${ }^{5}$ Nepean Hospital, Derby St, Penrith, NSW 2747, Australia

Full list of author information is available at the end of the article
}

acknowledged [8-10]. RV dysfunction is common in the ICU, but is often under-recognised in the clinical setting. Dysfunction of the right ventricle in sepsis is progressively more recognised, although this has not been studied to the same extent as the left ventricle [3, 4, 8-10].

RV dysfunction has been associated with increased mortality in sepsis $[4,8,14]$, although this has not been uniformly reported [11, 12]. RV dysfunction in sepsis may be characterised by one or more of the followingincreased RV dimensions [2, 8, 13], and impaired systolic and/or diastolic function as measured by B- or M-mode or doppler indices (Table 1) [3, 11, 17, 18].

Right-ventricular contraction mainly occurs in the longitudinal plane. This makes tricuspid annular plane systolic excursion (TAPSE) a suitable method of assessing 


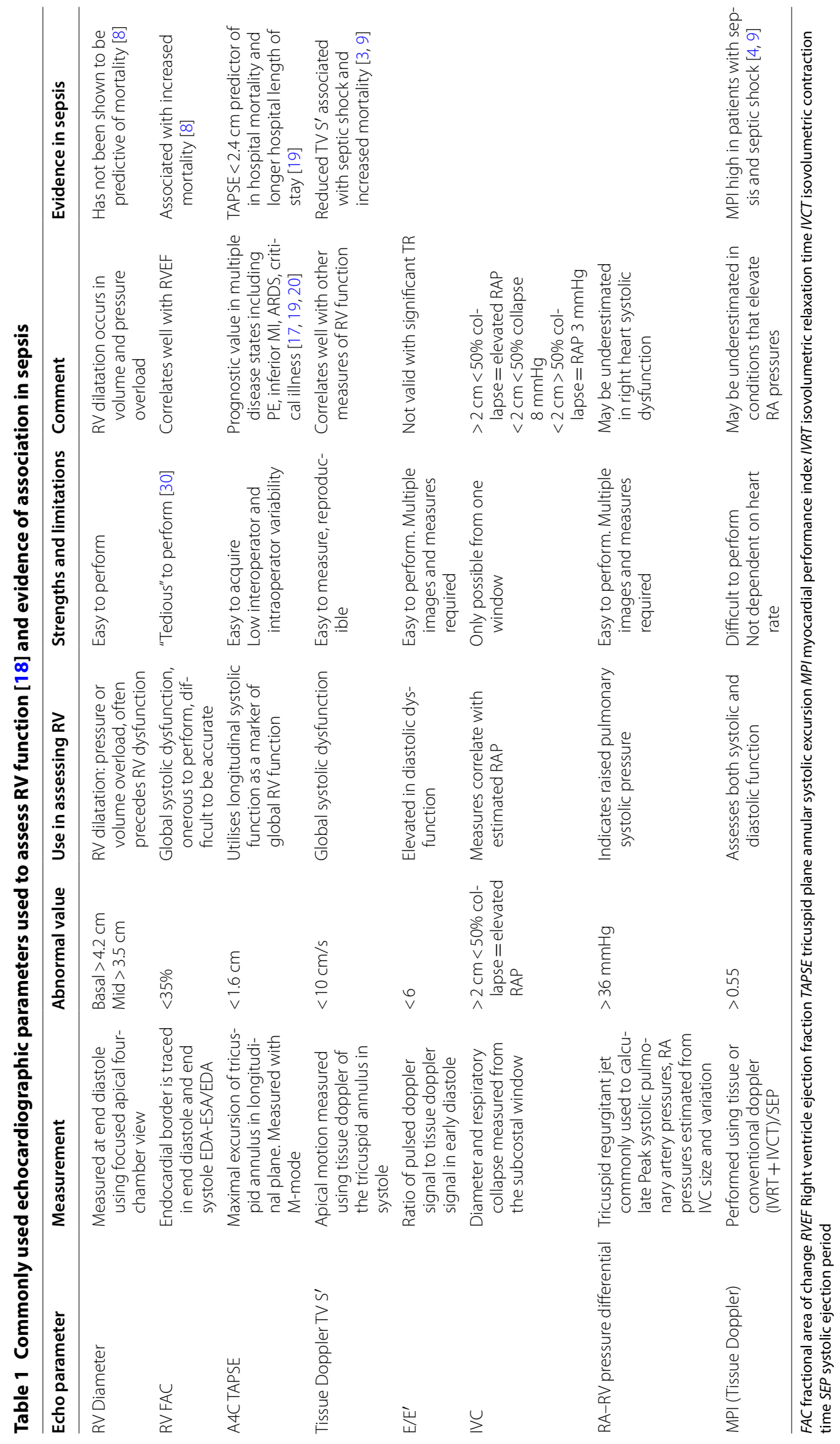


RV systolic function. TAPSE is usually performed from an apical four-chamber (A4C) window using M-mode across the annulus to evaluate longitudinal contraction (Fig. 1). TAPSE $>16 \mathrm{~mm}$ is considered normal; a value $<16 \mathrm{~mm}$ indicates reduced $\mathrm{RV}$ systolic function. TAPSE closely correlates with RV ejection fraction, and has been shown to be easy to perform, accurate, reproducible with little inter-observer variation $[14,15]$. The American Society of Echocardiography currently recommends using TAPSE as one of the tools to assess RV function [16]. It is an independent prognostic marker in critical illness [17] and specific pathologies including pulmonary embolus [18], inferior myocardial infarction [19], and Acute Respiratory Distress Syndrome [20]. However, the utility of TAPSE may be limited by the difficulty in obtaining the $\mathrm{A} 4 \mathrm{C}$ echo view. The $\mathrm{A} 4 \mathrm{C}$ window often requires repositioning of the patient. In the critically ill, mechanical ventilation, monitoring equipment, wounds, dressings, drains, high body mass index, or chronic lung disease can make imaging from the $\mathrm{A} 4 \mathrm{C}$ window challenging (Additional file 1) [7].

The subcostal view is often easier to obtain in the intensive-care population (Additional file 2) [6]. RV function as assessed in the subcostal view has previously been shown to correlate strongly with radionuclide scans [21]. Furthermore, assessment of the tricuspid annulus has been shown to be more frequently possible from the subcostal view [7]. Subcostal TAPSE may, therefore, be an alternative method of assessing RV dysfunction in the critically ill if the traditional A4C view is not available.

The primary aim of this retrospective study was to evaluate the feasibility and accuracy of subcostal TAPSE as a novel method of assessing RV function compared with the conventional TAPSE from the A4C view in intensivecare patients admitted with sepsis.

Sepsis was chosen as a condition that can result in reduced RV function, so that this method could be assessed with both normal and abnormal RV function. Second, this study assessed the association between echocardiographic indicators of RV dysfunction and adverse outcomes, in particular 90-day mortality.

\section{Methods}

\section{Design, setting, and participants}

This is a retrospective observational study performed in Nepean Hospital Intensive Care Unit. Septic patients admitted to the ICU between August 2012 and March 2014 were identified for inclusion in this study.

\section{Main outcome measures}

The primary outcome measure was the comparative accuracy of the TAPSE measurement obtained from the subcostal window compared with the conventional
TAPSE measure from the apical four-chamber view. Secondary measures included 90-day mortality.

\section{Data collection}

Patients without echocardiograms, inadequate acoustic windows for analysis, and those who did not meet sepsis criteria were excluded. This study was approved by the Nepean Blue Mountains Local Health District Human Research Ethics Committee (study ref: 14/34) and did not require individual patient consent due to its retrospective and observational nature.

This is intended to serve as a pilot study for future prospective research into the role of RV dysfunction in sepsis outcomes. As such, it was anticipated that approximately 50 participants would be required. The data were obtained from a computerised database.

\section{Echocardiography}

Images were evaluated for conventional measures of RV function: RV dimension, A4C TAPSE, velocity of tricuspid annular systolic motion (TV $\mathrm{S}^{\prime}$ ), fractional area change (FAC), tricuspid valve regurgitation peak velocity, estimated RA-RV pressure difference, and IVC diameter in accordance with the latest American Society of Echocardiography guidelines (Table 1) [17]. The subcostal views were given to a different assessor in a blinded fashion, from which the subcostal TAPSE values were measured (S.O.). The subcostal TAPSE was performed using B-mode imaging, in contrast to A4C TAPSE, which utilises M-mode (Fig. 1a). The tricuspid annulus was identified in diastole, and a cursor placed over it. Having evaluated the longitudinal axis, the image was then progressed to systole where a second cursor was placed over the tricuspid annulus. The distance between the two points is the subcostal TAPSE (Fig. 1b).

\section{Statistical methods}

Statistical analysis was performed using JMP 10.0.0 software (SAS Institute Inc., Cary, NC, USA). Continuous data are described using mean \pm standard deviation (SD) or median \pm interquartile range (IQR) and were analysed between groups using analysis of variance and $t$ test. Categorical data are expressed as number of patients and percentage of group and comparisons are made by Pearson's Chi-squared test or Fisher's exact test if less than five patients were in a specific group. Probability values are considered two-sided and a p value $<0.05$ was considered significant. The correlation between subcostal and A4C TAPSE values was assessed using a Bland-Altman plot and paired $t$ test. Categorisation of RV function: "normal" versus "abnormal" function was compared by McNemar's test, confidence intervals are "exact" Clopper-Pearson confidence intervals. Inter- and intra-observer subcostal 

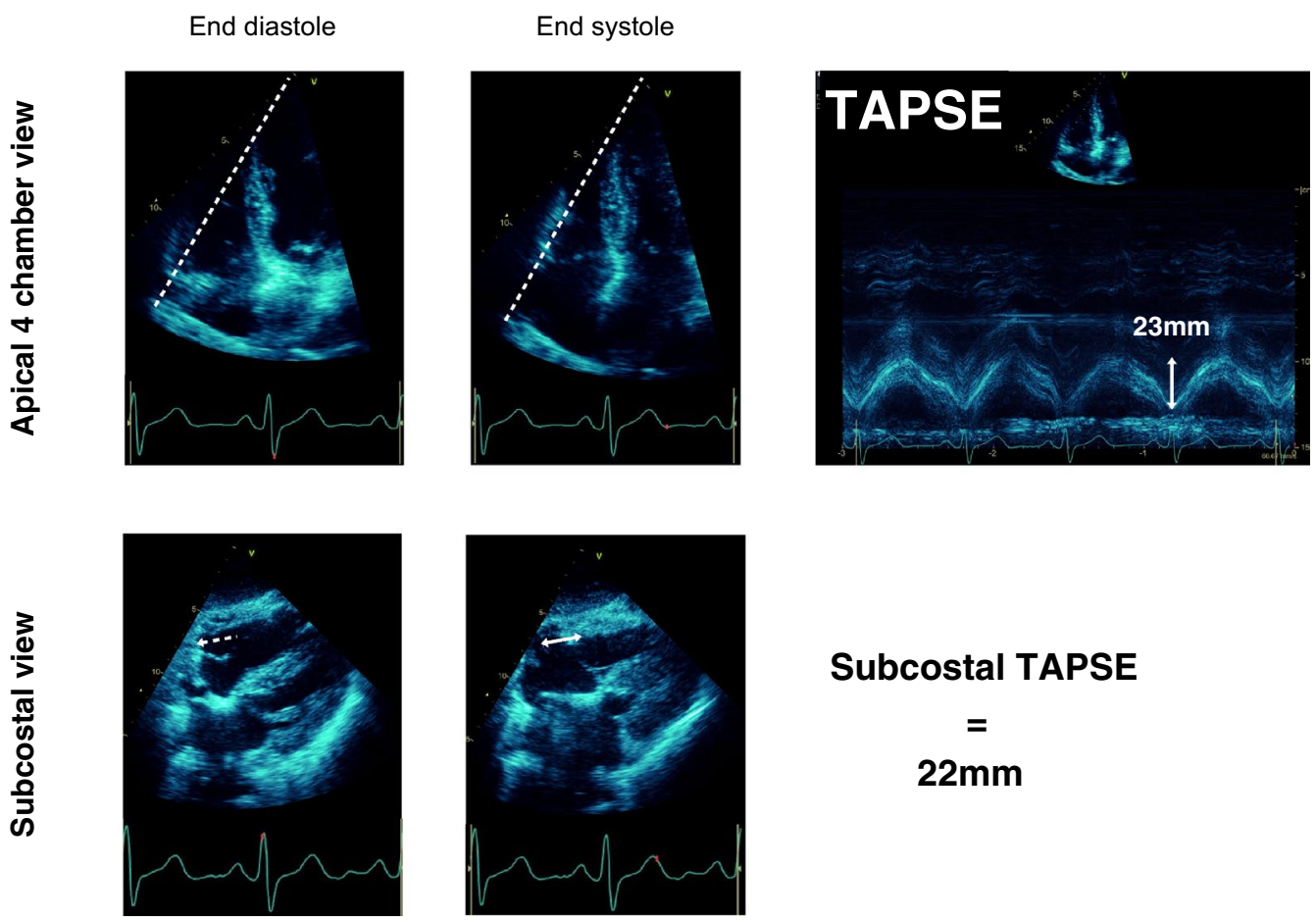

\section{Subcostal TAPSE \\ $=$ \\ $22 \mathrm{~mm}$}

Fig. 1 TAPSE measurement. a A4C TAPSE: standard method from the A4C window using M-mode. b Subcostal TAPSE: measured from subcostal window using B-mode imaging and marker

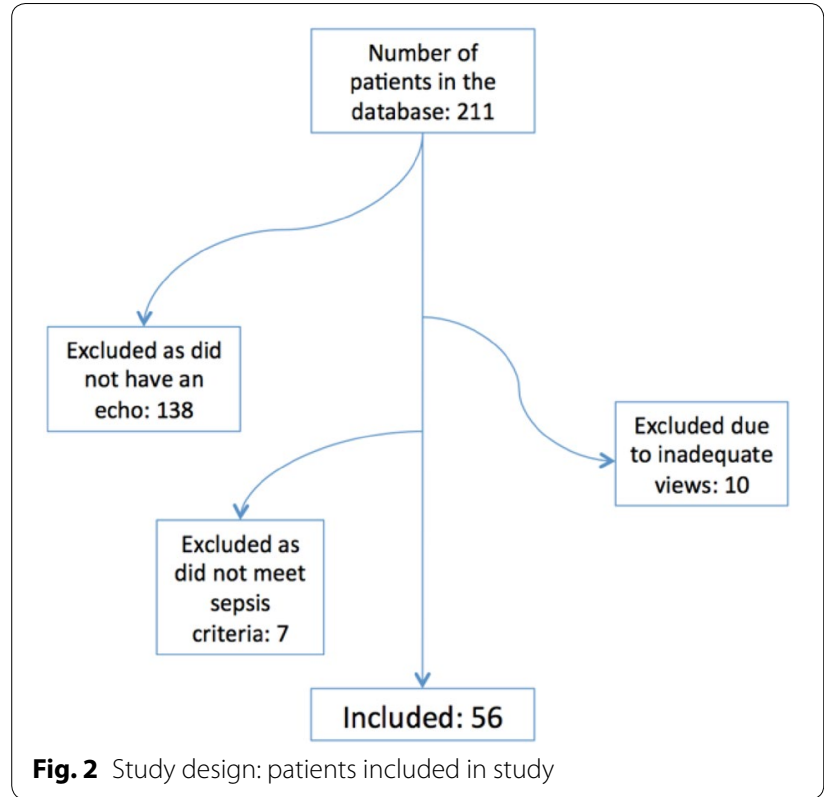

TAPSE variability was performed on a random $40 \%$ of the study population (23/58 patients) and assessed by BlandAltman plots as absolute difference and expressed as a percentage of their mean. Mortality was assessed using univariate logistic regression for continuous data and Chi-squared tests for categorical data.

\section{Results}

211 patients were admitted to the intensive-care unit with a diagnosis of sepsis during the study period. 138 patients were excluded as an echo was not performed during their ICU stay, 10 patients were excluded due to inadequate echo views for evaluation (6 inadequate $\mathrm{A} 4 \mathrm{C}$ views, 4 subcostal), and 8 patients were excluded as they did not meet criteria [22] for sepsis or septic shock (Fig. 2). A total of 56 patients were included in this study with an average age of 61 (SD 15.3) and mean APACHE III score of 67.5 (SD 27). The characteristics of the study population are described in Table 2.

\section{A4C vs subcostal TAPSE}

TAPSE from A4C and subcostal views showed a mean difference of $1.2 \mathrm{~mm}$ (CI 0.04-2.36). However, the BlandAltman plot (Fig. 3) demonstrates most data points outside this confidence interval, with fanning at high TAPSE values.

A difference between subcostal TAPSE and A4C TAPSE of less than $3 \mathrm{~mm}$ is present in $92.1 \%$ of data pairs when TAPSE $<24 \mathrm{~mm} ; 96.7 \%$ of data pairs 


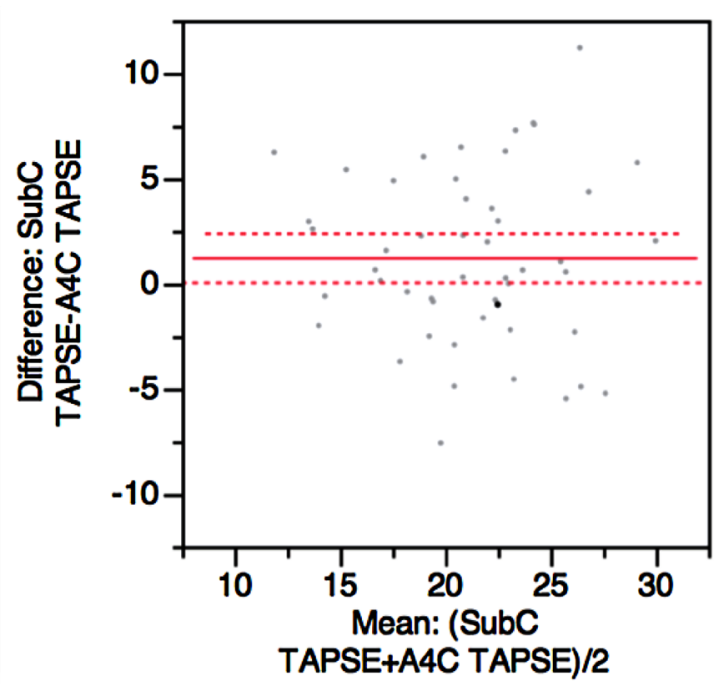

Fig. 3 Bland-Altman plot demonstrating mean difference between A4C and Subcostal TAPSE

Table 2 Characteristics of study population

\begin{tabular}{llll}
\hline Characteristics & \multicolumn{2}{l}{$\mathbf{9 0}$ day mortality } & \\
\cline { 2 - 4 } & Survivors & Non-survivors & $\boldsymbol{p}$ value \\
\hline Age (mean+SD) & $59.9 \pm 16.1$ & $65.1 \pm 12.9$ & 0.2 \\
Female & $22(54.7 \%)$ & $11(73.3 \%)$ & 0.23 \\
Male & $19(46.3 \%)$ & $4(26.7 \%)$ & \\
Source of sepsis & & & \\
Respiratory & $30(75 \%)$ & $11(73.3 \%)$ & 0.7 \\
Skin & $3(7.5 \%)$ & $1(6.7 \%)$ & 0.9 \\
Urological & $4(10 \%)$ & $0(0 \%)$ & 0.3 \\
Gastrointestinal & $1(2.5 \%)$ & $1(6.7 \%)$ & 0.2 \\
Other & $1(2.5 \%)$ & $1(6.7 \%)$ & 0.47 \\
Unknown & $1(2.5 \%)$ & $2(13.33 \%)$ & 0.17 \\
Apache score mean (SD) & $59.8(20.1)$ & $102.3(27.6)$ & 0.05 \\
\hline
\end{tabular}

when TAPSE $<22 \mathrm{~mm}$; and $100 \%$ of data pairs when TAPSE $<19 \mathrm{~mm}$. At TAPSE values greater than or equal to $24 \mathrm{~mm}, 63.6 \%$ of values had a difference $<3 \mathrm{~mm}$. Intra-observer variability was good with mean absolute difference $( \pm S D)$ of $2.3 \mathrm{~mm}( \pm 2.7)$ and expressed as a percentage of the mean $11.4 \%( \pm 9)$. Inter-observer variability was adequate with mean absolute difference of $3.4 \mathrm{~mm}( \pm 2.4)$ and expressed as percentage of the mean $15.8 \%( \pm 11)$.

When subcostal TAPSE is compared with A4C TAPSE as the gold standard, it identifies "Abnormal" TAPSE with a sensitivity of 97.8\% (CI 88.2-99.9\%) and specificity of $87.5 \%$ (47.4-99.7\%).
Right-ventricular dysfunction and 90-day mortality No correlation was seen between either TAPSE measures of RV dysfunction and 90-day mortality (A4C TAPSE $\mathrm{OR}=1.05, \mathrm{CI} 0.92-1.20 ; \mathrm{p}=0.48 ;$ subcostal TAPSE $\mathrm{OR}=0.98$, CI $0.86-1.11 \mathrm{p}=0.74)$. However, when categorised, "abnormal" TAPSE was associated with higher mortality compared with "normal" TAPSE, although it did not reach statistical significance $(57.1 \%$ vs $23.9 \%$ $\mathrm{p}=0.09$ ). Increased RV dimensions at the basal and midlevels were associated with increased 90-day mortality (basal dimensions $\mathrm{OR}=1.16, \mathrm{CI} 1.05-1.32, \mathrm{p}=0.004$; mid-dimensions $\mathrm{OR}=1.12$ CI $1.02-1.25, \mathrm{p}=0.012$ ). No other measures of RV dysfunction were associated with increased mortality.

\section{Discussion}

\section{Apical four-chamber TAPSE versus subcostal TAPSE}

In this retrospective, observational study, we demonstrated that subcostal TAPSE correlated well with the conventional A4C TAPSE at low and moderate TAPSE values, with most differences less than $3 \mathrm{~mm}$. The negative prognostic significance of TAPSE values has been reported at values $<18 \mathrm{~mm}$ [23], in sepsis, increased mortality has been found at TAPSE values less than $24 \mathrm{~mm}$ [17]. It is in this region of interest where subcostal (SC) TAPSE had reasonable accuracy compared with A4C TAPSE. The difference of less than $3 \mathrm{~mm}$ is considered to be a clinically acceptable difference. SC TAPSE maintained accuracy when categorising "abnormal" and "normal" TAPSE values.

The mean difference between measures was small; however, most data points fell outside of the confidence intervals, limiting the utility of that measure. There is increased variance at high TAPSE values. The reason for this may be due to translational movement in a hyperdynamic heart or inaccuracies in identifying the axis of contraction with vigorous movement. Although this limits the accuracy of the absolute value of subcostal TAPSE in these circumstances, it does not impede the utility of subcostal TAPSE altogether, as at high values TAPSE is considered to be normal and is unlikely to influence prognostication or interventions and would support an assessment of normal RV function.

Although this data set is small and retrospective, it supports the feasibility of using subcostal TAPSE. Further research is required before implementing its use in clinical practice, particularly ensuring minimal inter-observer variability and discrimination of clinically relevant outcomes.

With greater understanding of the importance of RV dysfunction in critical illness, accurate transthoracic echo assessment of the RV is a crucial tool in managing 
intensive-care patients. Subjective assessment of RV function has been shown to only have fair reliability when performed by ICU specialists adequately trained in echo, but only for initial exclusion of significant RV pathology. Quantification of RV function is important to ensure accurate estimation of performance [24].

TAPSE is a commonly used tool in cardiac function analysis; however, its utility is limited in the critically ill due to difficulty obtaining A4C views. Inability to obtain TAPSE has been reported to range from 6 to $25 \%$ of cases [25-27]. Other measures of RV function such as Fractional Area of Change have been described as "tedious" with TAPSE comparably easier [28]. Subcostal views have previously been shown to be comparable to A4C views in the assessment of RV function [21]. Most TAPSE measurements take less than $30 \mathrm{~s}$ to perform. The relative ease of obtaining images from the subcostal window makes this an attractive alternative in the critically ill.

The use of the subcostal window to assess the RV has been increasingly considered, although with varied success $[7,29]$. Subcostal echocardiographic assessment of tricuspid annular kick (SEATAK) has been purported as an alternative to TAPSE in critically ill patients [7]. SEATAK utilises the subcostal short-axis view; using M-mode, the cursor placed over the tricuspid annulus and measured in a similar way to A4C TAPSE measurements. This study confirmed the feasibility of using the subcostal view; however, the angle of M-mode may underestimate RV function. Subcostal TAPSE has the advantage of identifying and measuring in the longitudinal axis along which the RV contracts.

\section{RV function and mortality}

RV dysfunction in critical illness and sepsis, in particular, has been associated with increased mortality, [11,30]; however, the association between specific echocardiographic measures and outcomes have not been consistently reported $[3,4,9,13,31]$.

TAPSE has been demonstrated to accurately measure RV function and predict mortality in a variety of conditions [14, 18-20, 25]. Reduced TAPSE has been associated with increased mortality and longer hospital length of stay [17], although this finding has not been replicated [4]. In this study, there was no association between TAPSE and 90-day mortality. There are a number of possible reasons for this: the numbers in this study are small and may not suffice to show any difference if present; there are a complex variety of factors that result in adverse outcomes in sepsis; TAPSE alone may not be a prognostically significant marker. In addition, the timing of the echocardiogram was not controlled for. As such, the findings may be affected by fluid resuscitation, inotropic and ventilator support or the natural course of the illness. Further investigation is required to assess the utility of subcostal TAPSE in assessing RV function in sepsis and its role in prognostication. In particular, standardisation of timing of the echocardiogram (such as when inotropic or vasoactive medications are commenced, or serially at predetermined times during the ICU stay) may aid in identifying an association with RV dysfunction and outcomes. Based on these data, a study to detect an association between TAPSE and mortality would require a sample size of at least 638 utilising a $1 \mathrm{~mm}$ difference in TAPSE with a standard deviation of 4.5, an alpha of 0.05 and $80 \%$ power.

Interestingly, there was an association between increased RV diameter and mortality in this population. The reason for this association is not clear; however, increased end-diastolic volume (EDV) has previously reported in sepsis, although it has not been associated with an increase in mortality $[2,8,32]$. Increase in RV diameter occurs in both pressure and volume overload [33-35]. We hypothesise that EDV may be a surrogate for fluid overload. As excess fluid has been associated with increased mortality in sepsis [36-38], this provides a possible link between the RV measurements and mortality outcomes. Other causes of right-ventricular dilatation, such as pulmonary hypertension associated with sepsis and high intrathoracic pressures with positive pressure ventilation, may contribute to RV dilatation, but are beyond the scope of this study. Further investigation is required to evaluate the relationship, if any, between fluid status, RV dimensions, and mortality.

\section{Strengths and limitations}

The main strengths of this study are that it supports the feasibility of a novel echo technique and it generates further hypotheses regarding the role of the RV in sepsis and provides direction for further research in this area. This study is limited by its retrospective nature and small numbers. A number of patients were excluded, because there were no echocardiograms performed. In addition, the timing of the echo was not controlled for, which may influence the accuracy of using TAPSE as a prognostic tool. The exclusion of patients without echocardiograms would not impact our primary research aim, and the overall numbers excluded for inadequate subcostal views were small. Exclusion of patients may have reduced overall numbers, so that finding associations, if any exist, between adverse outcomes and RV dysfunction is less likely. Reassuringly, the association between $\mathrm{A} 4 \mathrm{C}$ and subcostal TAPSE that has been found is likely to be robust, within the limits of a small study, as the patient characteristics are similar to patient groups in other published sepsis trials [38]. 
Another limitation of this trial was that one clinician performed all subcostal TAPSE measurements. Despite this, inter-observer variation was adequate, and intra-observer variation was good in a subset of measures. This method needs to be further assessed before general use ensuring accuracy persists with multiple clinicians.

\section{Conclusion}

Subcostal TAPSE correlates well with the conventional A4C TAPSE at low and moderate TAPSE values and categorises TAPSE into "normal" and "abnormal" with good accuracy. SC TAPSE may be a surrogate method for RV analysis in the critically ill where apical views are challenging. Subcostal TAPSE is quick, easy, and provides significant information about RV function. With growing use of point of care ultrasound and focused echo in critical care, subcostal TAPSE could quickly and easily be added to the examination; however, confirmation of minimal inter-observer variability is required first. This study suggests that increased EDV may be associated with increased mortality. The importance of RV dysfunction in sepsis and its sequelae require further exploration.

\section{Supplementary information}

Supplementary information accompanies this paper at https://doi. org/10.1186/s13089-019-0134-7.

Additional file 1: Video S1. Apical four-chamber image was challenging to obtain and the tricuspid annulus is less well seen.

Additional file 2: Video S2. Subcostal image from the same patient, the tricuspid annulus has better definition.

\section{Abbreviations \\ A4C: apical four chamber; EDV: end diastolic volume; eGFR: estimated glo- merular filtration rate; FAC: fractional area change; ICU: intensive-care unit; RV: right ventricle; SC: subcostal; SEATAK: subcostal echocardiographic assessment of tricuspid annular kick; TAPSE: tricuspid annular plane systolic excursion; TV $S^{\prime}$ : tricuspid annular systolic motion velocity.}

\section{Acknowledgements}

The authors would like to thank sonographers of the Nepean Intensive Care Cardiovascular Ultrasound Laboratory for their expertise and skill in assisting in acquiring echocardiography studies, and Mr. Mark Hamilton for manuscript editing. In addition, we would like to thank Dr. Vijeth Bhat for his help in performing inter-rater variability analysis.

\section{Authors' contributions}

ABM performed data collection and statistical analysis and prepared the manuscript. RB assisted with the ethics application, data collection, and drafting of the manuscript. DC assisted with study design, data collection, and drafting of the manuscript. AJl assisted with study design. SO conceived and designed the study, performed measurements, and revised the manuscript. AM assisted with study design and revision of the manuscript. All authors read and approved the final manuscript.
Funding

Not applicable.

\section{Availability of data materials}

The data sets generated and analysed during this study are available from the corresponding author on reasonable request.

\section{Ethics approval and consent to participate}

This study was approved by the Nepean Blue Mountains Local Health District Human Research Ethics Committee (study ref: 14/34) and did not require individual patient consent due to its retrospective and observational nature.

\section{Consent for publication}

Consent for use of de-identified images contained in this article was given by the individuals involved.

\section{Competing interests}

The authors declare that they have no competing interests.

\section{Author details}

${ }^{1}$ Alice Springs Hospital, Gap Road, The Gap, NT 0870, Australia. ${ }^{2}$ Gold Coast University Hospital, Hospital Boulevard, Southport, QLD 4215, Australia. ${ }^{3}$ Royal Darwin Hospital, Rocklands Dr, Tiwi, NT 0810, Australia. ${ }^{4}$ St George Hospital, Gray St, Kogarah, NSW 2217, Australia. ${ }^{5}$ Nepean Hospital, Derby St, Penrith, NSW 2747, Australia.

Received: 27 November 2018 Accepted: 13 August 2019 Published online: 27 August 2019

\section{References}

1. Dalla K, Hallman C, Bech-Hanssen O, Haney M, Ricksten S-E (2015) Strain echocardiography identifies impaired longitudinal systolic function in patients with septic shock and preserved ejection fraction. Cardiovasc Ultrasound. https://doi.org/10.1186/s12947-015-0025-4

2. Hoffman M, Greenfield L, Sugerman H, Tatum J (1983) unsuspected right ventricular dysfunction in shock and sepsis. Ann Surg 198(3):307-319. https://doi.org/10.1097/00000658-198309000-00007

3. Furian T, Aguiar C, Prado Ket al (2012) Ventricular dysfunction and dilation in severe sepsis and septic shock: relation to endothelial function and mortality. J Crit Care 27(3):319.e9-319.e15. https://doi.org/10.1016/j. jcrc.2011.06.017

4. Vallabhajosyula S, Kumar M, Pandompatam G et al (2017) Prognostic impact of isolated right ventricular dysfunction in sepsis and septic shock: an 8-year historical cohort study. Annals of Intensive Care. https:// doi.org/10.1186/s13613-017-0319-9

5. Vincent J-L, Rhodes A, Perel A et al (2011) Clinical review: update on hemodynamic monitoring - a consensus of 16. Crit Care 15(4):229. https ://doi.org/10.1186/cc10291

6. Bowcock EM, Morris IS, McLean AS, Orde SR (2017) Basic critical care echocardiography: how many studies equate to competence? A pilot study using high fidelity echocardiography simulation. J Intensive Care Soc. https://doi.org/10.1177/1751143717700166

7. Díaz-Gómez JL, Alvarez AB, Danaraj JJ et al (2016) A novel semiquantitative assessment of right ventricular systolic function with a modified subcostal echocardiographic view. Echocardiography 34(1):44-52. https ://doi.org/10.1111/echo.13400

8. Singh RK, Kumar S, Nadig S et al (2016) Right heart in septic shock: prospective observational study. J Intensive Care. https://doi.org/10.1186/ s40560-016-0159-y

9. Harmankaya A, Akilli H, Gul M et al (2013) Assessment of right ventricular functions in patients with sepsis, severe sepsis and septic shock and its prognostic importance: a tissue Doppler study. J Crit Care 28(6):1111. e7-1111.e11. https://doi.org/10.1016/j.jcrc.2013.07.059

10. Orde SR, Pulido JN, Masaki M et al (2014) Outcome prediction in sepsis: speckle tracking echocardiography based assessment of myocardial function. Crit Care 18(4):R149. https://doi.org/10.1186/cc13987

11. Redl G, Germann P, Plattner H, Hammerle A (1993) Right ventricular function in early septic shock states. Intensive Care Med 19(1):3-7. https://doi. org/10.1007/BF01709270 
12. Pulido JN, Afessa B, Masaki M et al (2012) Clinical spectrum, frequency, and significance of myocardial dysfunction in severe sepsis and septic shock. Mayo Clin Proc 87(7):620-628. https://doi.org/10.1016/j.mayoc p.2012.01.018

13. Landesberg G, Gilon D, Meroz Y et al (2012) Diastolic dysfunction and mortality in severe sepsis and septic shock. Eur Heart J 33(7):895-903. https://doi.org/10.1093/eurheartj/ehr351

14. Forfia PR, Fisher MR, Mathai SC et al (2006) Tricuspid annular displacement predicts survival in pulmonary hypertension. Am J Respir Crit Care Med 174(9):1034-1041. https://doi.org/10.1164/rccm.200604-5470C

15. Kaul S, Tei C, Hopkins JM, Shah PM (1984) Assessment of right ventricular function using two-dimensional echocardiography. Am Heart J 107(3):526-531. https://doi.org/10.1016/0002-8703(84)90095-4

16. Rudski LG, Lai WW, Afilalo J et al (2010) Guidelines for the echocardiographic assessment of the right heart in adults: a report from the American Society of Echocardiography endorsed by the European Association of Echocardiography, a registered branch of the European Society of Cardiology, and the Canadian Society of Echocardiography. J Am Soc Echocardiogr 23(7):685-713. https://doi.org/10.1016/j.echo.2010.05.010 (quiz 786-8)

17. Gajanana D, Seetha Rammohan H, Alli O et al (2015) Tricuspid annular plane systolic excursion and its association with mortality in critically ill patients. Echocardiography 32(8):1222-1227. https://doi.org/10.1111/ echo.12926

18. Lobo JL, Holley A, Tapson V et al (2014) Prognostic significance of tricuspid annular displacement in normotensive patients with acute symptomatic pulmonary embolism. J Thromb Haemost 12(7):1020-1027. https://doi.org/10.1111/jth.12589

19. Hayrapetyan HG, Adamyan KG (2013) Prognostic usefulness of the tricuspid annular plane systolic excursion in patients with acute inferior myocardial infarction. Eur Heart J 34(suppl 1):P1280-P1280. https://doi. org/10.1093/eurheartj/eht308.P1280

20. Osman D, Monnet $X$, Castelain V et al (2008) Incidence and prognostic value of right ventricular failure in acute respiratory distress syndrome. Intensive Care Med 35(1):69-76. https://doi.org/10.1007/s0013 4-008-1307-1

21. Starling MR, Crawford MH, Sorensen SG, O'Rourke RA (1982) A new twodimensional echocardiographic technique for evaluating right ventricular size and performance in patients with obstructive lung disease. Circulation 66(3):612-620. https://doi.org/10.1161/01.CIR.66.3.612

22. Dellinger RP, Levy MM, Rhodes A et al (2013) Surviving sepsis campaign. Crit Care Med 41(2):580-637. https://doi.org/10.1097/CCM.0b013e3182 7e83af

23. Schmid E, Hilberath J, Blumenstock $\mathrm{G}$ et al (2015) Tricuspid annular plane systolic excursion (TAPSE) predicts poor outcome in patients undergoing acute pulmonary embolectomy. Heart Lung Vessel 7:151-158

24. Orde S, Slama M, Yastrebov K, Mclean A, Huang S (2019) Subjective right ventricle assessment by echo qualified intensive care specialists assessing agreement with objective measures. Crit Care. https://doi.org/10.1186/ s13054-019-2375-z

25. Damy T, Kallvikbacka-Bennett A, Goode K et al (2012) Prevalence of, associations with, and prognostic value of tricuspid annular plane systolic excursion (TAPSE) among out-patients referred for the evaluation of heart failure. J Cardiac Fail 18(3):216-225. https://doi.org/10.1016/j.cardf ail.2011.12.003

26. Kjaergaard J, Petersen C, Kjaer A, Schaadt B, Oh J, Hassager C (2006) Evaluation of right ventricular volume and function by $2 \mathrm{D}$ and $3 \mathrm{D}$ echocardiography compared to MRI. Eur J Echocardiogr 7(6):430-438. https://doi. org/10.1016/j.euje.2005.10.009

27. Ueti OM (2002) Assessment of right ventricular function with Doppler echocardiographic indices derived from tricuspid annular motion: comparison with radionuclide angiography. Heart 88(3):244-248. https://doi. org/10.1136/heart.88.3.244

28. López-Candales A, Rajagopalan N, Saxena N, Gulyasy B, Edelman K, Bazaz $R$ (2006) Right ventricular systolic function is not the sole determinant of tricuspid annular motion. Am J Cardiol 98(7):973-977. https://doi. org/10.1016/j.amjcard.2006.04.041

29. Maizel J, Salhi A, Tribouiloy C et al (2013) The subxiphoid view cannot replace the apical view for transthoracic echocardiographic assessment of hemodynamic status. Crit Care. https://doi.org/10.1186/cc12869

30. Dhainaut JF, Lanore JJ, de Gournay JM et al (1988) Right ventricular dysfunction in patients with septic shock. Intensive Care Med 14(S1):488491. https://doi.org/10.1007/BF00256967

31. Chan C, Klinger J (2008) The right ventricle in sepsis. Clin Chest Med 29(4):661-676. https://doi.org/10.1016/j.ccm.2008.07.002

32. Mitsuo T, Shimazaki S, Matsuda H (1992) Right ventricular dysfunction in septic patients. Crit Care Med 20(5):630-634. https://doi. org/10.1097/00003246-199205000-00014

33. Naeije R, Badagliacca R (2017) The overloaded right heart and ventricular interdependence. Cardiovasc Res 113:1474-1485. https://doi. org/10.1093/cvr/cvx160

34. Louie EK, Lin SS, Reynertson SI (1995) Pressure and volume loading of the right ventricle have opposite effects on left ventricular ejection fraction. Circulation 92(4):819-824. https://doi.org/10.1161/circ.92.4.819

35. Shah AS, Atkins BZ, Hata JA et al (2000) Early effects of right ventricular volume overload on ventricular performance and $\beta$-adrenergic signaling. J Thorac Cardiovasc Surg 120(2):342-349. https://doi.org/10.1067/ mtc.2000.107278

36. Malbrain MLNG, Marik PE, Witters I et al (2014) Fluid overload, de-resuscitation, and outcomes in critically ill or injured patients: a systematic review with suggestions for clinical practice. Anaesthesiol Intensive Ther 46(5):361-380. https://doi.org/10.5603/AIT.2014.0060

37. Maitland K, Kiguli S, Opoka RO et al (2011) Mortality after fluid bolus in african children with severe infection. N Engl J Med 364(26):2483-2495. https://doi.org/10.1056/NEJMoa1101549

38. Russell JA, Walley KR, Singer J et al (2008) Vasopressin versus norepinephrine infusion in patients with septic shock. N Engl J Med 358(9):877-887. https://doi.org/10.1056/NEJMoa067373

\section{Publisher's Note}

Springer Nature remains neutral with regard to jurisdictional claims in published maps and institutional affiliations.

\section{Submit your manuscript to a SpringerOpen ${ }^{\circ}$ journal and benefit from:}

- Convenient online submission

- Rigorous peer review

- Open access: articles freely available online

- High visibility within the field

- Retaining the copyright to your article

Submit your next manuscript at springeropen.com 